\title{
Delve into Research Ethics
}

SADJ October 2019, Vol. 74 No. 9 p513 - p514

WG Evans

The old adage "Publish or Perish" ...so frequently repeated, so often emphasized. And correct, the list of publications is often the first item considered when a CV is appraised, when a job interview is held. Does the pressure to have his/her name in print at the head of a research article force a researcher to consider cutting corners, to make assumptions that critical ethics standards are being upheld even when no direct effort has been made to confirm that status?

Every responsible researcher is so well aware of this dilemma. Not only is there the pressure to publish but in many cases there is the pressure to publish first... before competing researchers manage to secure pages in the journals. It may be pertinent to consider the sage guidelines of the Human Sciences Research Council (HSRC), supported by a paper published by the American Psychological Association.

The HSRC published advice on Research Ethics in 2019, listing four principles which researchers should "uphold and respect":

1. Principle of Respect and Protection

2. Principle of Transparency

3. Principle of Scientific and Academic Professionalism

4. Principle of Accountability

The American Psychological Association (APA) took a different approach in 2003 and published their five principles for research ethics:

1. Discuss intellectual property frankly

2. Be conscious of multiple roles

3. Follow Informed Consent rules

4. Respect confidentiality and privacy

5. Tap into ethics resources

Are these guidelines really disparate and if so will that lead to confounding the earnest researcher?

In discussing the Principle of Respect and Protection, the HSRC focuses at the start on the community, making the pertinent statement that "research should preferably be undertaken with, and not merely on, the identified community". This may reflect a growing awareness that research has been carried out in the community setting, the results have been published... and yet there has been little feedback to the community, nor have there been many benefits. Ethical research would certainly include effective feedback to a participating community.

It is in this first Principle that the HSRC considers Informed Consent, observing that the researcher must respect the autonomy and protect the welfare of all participants... and that Informed Consent must be secured from all participants. The APA however accord a separate Principle to this important aspect of conducting research. Their Principle "Follow informed consent rules" dictates that individuals who are participating voluntarily in the research should do so only with full knowledge of relevant risks and benefits. The APA goes on to list the factors about which participants should be informed:

- The purpose of the research, expected duration and procedures.

- Participants' rights to decline to participate and to withdraw from the research once it has started, as well as the anticipated consequences of doing so.

- Reasonably foreseeable factors that may influence their willingness to participate, such as potential risks, discomfort or adverse effects.

- Any prospective research benefits.

- Limits of confidentiality, such as data coding, disposal, sharing and archiving, and when confidentiality must be broken.

- Incentives for participation.

- Who participants can contact with questions.

- If the research involves treatment, individuals must be fully informed about the experimental nature of the treatment and about services which will or will not be available to participants.

The APA warns that a signed Consent Form does not reduce the responsibility to complete the full process of informing the volunteer.

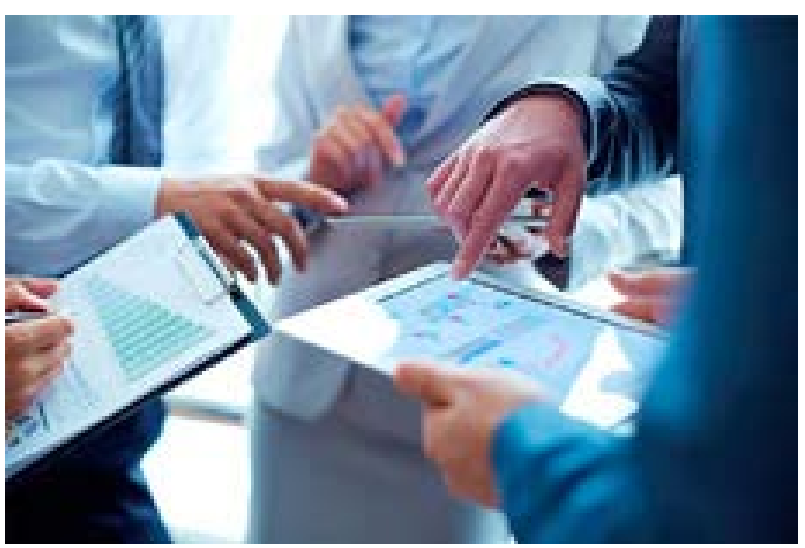

Coming in again on the issue of Informed Consent the HSRC observes in Principle 1 "Respect and protection" that the researcher must be especially concerned about the rights and interests of vulnerable subjects such as children or the elderly. The first precepts mentioned are the avoidance of harm, providing benefit whenever possible and acting justly. But several of the factors 
dealt with by the APA under their third Principle, "Follow Informed Consent Rules" are considered by the HSRC under their heading "Principles of Transparency" when they mention that "participants should be clearly briefed on the aims and implications of the research as well as possible outcomes and benefits."

Thus far in the exploration of the principles proposed by these two erudite bodies we have seen considerable overlap, be that under disparate headings. However, the HSRC now introduces a unique consideration... "The Principle of Scientific and Academic Professionalism", commenting that researchers should conduct their research in accordance with the professional code of the Association of which they are members, should not misuse their positions or knowledge for personal gain and should aim at all times to achieve the highest possible level of scientific quality in their research. These principles ring true for members of SADA, all will agree.

The HRSC document also includes a fifth Principle... "Accountabilty". Researchers are exhorted to ensure they have written mandates in which the general conditions and terms of the research are spelt out... obviously this applies when there are sponsors or clients involved in the research.

The agreement ensures that information is provided at the conclusion of the research but at the same time there should be restrictions on possible interference during the course of the study. Perhaps the reader may expect a modicum of duplication between Principle One of the APA (Discuss intellectual property frankly) and Principle Two of the HSRC (Transparency).
But these Principles are not quite a close as may have been expected. The HSRC commence description of their Principle by listing factors which may be applicable to Informed Consent, for example that the participants should be clearly briefed on the aims and implications of the research. The concepts are extended later to include the admonition that researchers should subscribe to the principles of honesty, transparency and scrutiny by the public and peers.

Some aspects of the APA Principle "Discuss intellectual property frankly" may also be discerned in the APA Principle Two "Be conscious of multiple roles", for both are in part concerned with recruiting students as participants in research studies. It is not ethical for a professor to use any coercion to induce students to participate... all must be voluntary and under full disclosure. The role of the supervisor should be clearly outlined and understood to avoid later possible conflict.

Ethics in Research is truly a broad canvas. Two organisations involved in research have shown that their emphasis on research ethics may vary, but that the foundations on which their policies have been built are in fact similar. A more comprehensive view and understanding of the ethical demands faced by researchers may be developed by considering all nine Principles. And the ninth Principle is "Tap into ethics resources"... yes, sage guidance indeed!

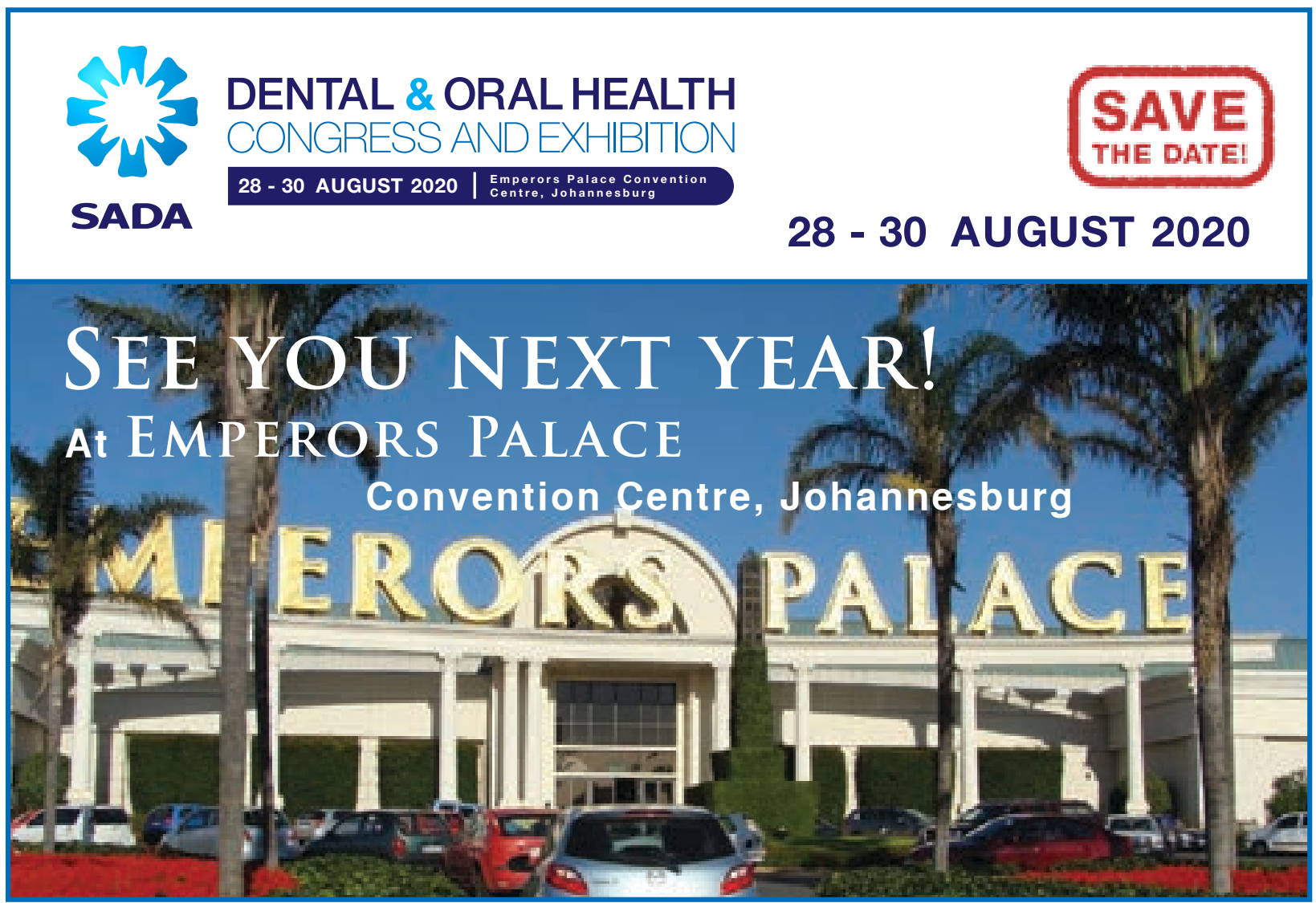

